\title{
Glial Cell
}

National Cancer Institute

\section{Source}

National Cancer Institute. Glial Cell. NCI Thesaurus. Code C12615.

A non-neuronal cell of the nervous system. Glial cells have diverse roles, including in regulation of neuronal survival and differentiation, maintenance of ion and neurotransmitter concentrations in the neuronal environment, synapse formation, and support of synaptic interactions and electrical signal propagation. 